\title{
The role of postmastectomy radiation in patients with ypNO breast cancer after neoadjuvant chemotherapy: a meta-analysis
}

\section{Ke Wang}

Second Affiliated Hospital of Zhejiang University

Xiaoyan Xiaoyan Jing

Second Affiliated Hospital of Zhejiang University

\section{Weilan Wang}

Second Affiliated Hospital of Zhejiang University

\section{Xiuyan Yu}

Second Affiliated Hospital of Zhejiang University

Jian Huang ( $\nabla$ Drhuangjian@zju.edu.cn )

Second Affiliated Hospital of Zhejiang University

\section{Research Article}

Keywords: Breast cancer, Neoadjuvant chemotherapy, Postmastectomy radiation therapy, Negative lymph nodes, Prognosis, Meta-analysis

Posted Date: December 17th, 2020

DOl: https://doi.org/10.21203/rs.3.rs-117619/v1

License: (1) This work is licensed under a Creative Commons Attribution 4.0 International License. Read Full License 


\section{Abstract}

Background: It has been demonstrated that postmastectomy radiation therapy (PMRT) was beneficial for breast cancer patients who are axillary lymph node-positive. However, the effectiveness of radiotherapy in pathological negative nodes (ypNO) after neoadjuvant chemotherapy (NAC) remains open to considerable debate. Here, we aim to evaluate whether PMRT improves loco-regional control and survival for such patients.

Methods: The literature from January 2004 to June 2019 was searched. The effects of PMRT on localregional recurrence (LRR) and survival was evaluated in a meta-analysis. Pooled relative risk (RR) values with $95 \%$ confidence intervals (Cls) were computed using random and fixed-effects models. Subgroup and heterogeneity analyses were also conducted.

Results: Ten studies that included 29,860 patients met the inclusion criteria. Pooled results showed that PMRT was associated with reduced LRR (RR, $0.38 ; 95 \% \mathrm{Cl}, 0.19-0.77, P=0.007)$, particularly in patients with stage III-IV breast cancer (RR, $0.16 ; 95 \% \mathrm{Cl}, 0.07-0.37, P<0.001)$. However, no significant difference in disease-free survival were observed with the addition of PMRT for ypNO patients (RR, $0.70 ; 95 \% \mathrm{Cl}$, $0.21-2.27, P=0.55)$. Also, there was no statistically significant association between radiotherapy with overall survival (RR, $0.81 ; 95 \% \mathrm{Cl}, 0.64-1.04, P=0.10)$.

Conclusions: Our meta-analysis indicated that PMRT might reduce local-regional recurrence for ypNO patients after NAC, but lake of benefit for survival outcomes. Prospective randomized clinical trial data will be needed to confirm our results.

\section{Background}

Neoadjuvant chemotherapy (NAC) is increasingly used in locally advanced breast cancer. The advantages of NAC include that it can reduce pathologic stage and increased potential breast conservation therapy, as well as upfront treatment of micrometastatic cancer [1, 2]. In the adjuvant setting, postmastectomy radiation therapy (PMRT) have shown significantly reduces recurrence in patients with positive lymph nodes after following systemic treatment [3-5]. However, the discrepancy in the response to NAC complicates the adjuvant setting treatment decision, and therefore, the role of PMRT in breast cancer with no evidence of residual pathologic nodal disease (ypNO) has remained controversial.

Recently, several retrospective studies found that PMRT was associated with improving both local control and survival in ypNO breast cancer patients [6-8]. A recent analysis reported that PMRT reduced localregional recurrence (LRR) in ypNO breast cancer cases, following primary systemic treatment [9]. Subgroup analysis further confirmed a significant survival benefit in patients with cT1-2N1 breast cancer. However, other retrospective data showed that patients with pathologically node-negative (ypN0) disease after NAC had smaller absolute rates of 5-year local-regional recurrence (LRR) (8\% in the PMRT group vs. 
$12 \%$ in the non-PMRT group) [10]. The results implied that there was no increase in the risk of LRR when PMRT was omitted.

The aim of gaining better insight into the effectiveness of PMRT in patients after NAC, we carried out the first comprehensive meta-analysis and systemic review on this topic, particularly those studies that evaluated patients presenting with clinically negative lymph nodes who achieved a favorable pathologic response to NAC. Then, we investigated the prognostic value of PMRT (presence vs. absence) on LRR and survival (DFS or OS), as well as performing subgroup analyses.

\section{Methods And Materials}

\section{Literature search}

In this systematic review and meta-analysis, literature in the PubMed database and major oncology congress abstracts were searched in June 2019 , and the following search terms were variably combined: "breast cancer," "breast carcinoma," "breast neoplasm," "neoadjuvant chemotherapy," "preoperative chemotherapy," "radiation therapy," "postmastectomy radiotherapy". As some trials concerning NAC and breast cancer prognosis may not have yet been published, we searched for relevant abstracts published in major international proceedings. We also reviewed references of relevant published trials to identify additional study articles.

\section{Eligibility criteria}

All studies that met the following criteria were included: patients diagnosed with breast cancer, achievement of a pathological negative node response to NAC, adequate data provided for estimating the relative risk (RR) for LRR and survival outcome, and original articles. Histological type and breast cancer status were not restricted. Exclusion criteria were as follows: studies published in a systematic review, commentaries, letters, or the study did not determine LRR or survival.

\section{Data extraction}

Two investigators independently extracted data from potentially eligible studies. Any disagreement was resolved by discussion. The data were collected directly from the publication: first author's name, country, publication year, number of patients, pathological stage, neoadjuvant chemotherapy, type of surgery, outcome and median follow-up duration. If LRR or survival information was not direct provided, we calculated the data from the available Kaplan-Meier curves to estimate the clinical outcomes [11]. The relevant information was carefully extracted according to the following three aspects: (1) PMRT was correlated with LRR in breast cancer and subtype; (2) PMRT was associated with DFS or OS; (3) the ypNO (include PCR) was used as eligible definition.

Pooled relative risk (RR) values with $95 \%$ confidence intervals (Cls) were calculated by random and fixedeffects models. The test for heterogeneity was using Cochran's $Q$ method and the $I^{2}$ statistic. When the P- 
value was more than 0.05 , a fixed-effects model estimate was presented. Otherwise, the random-effects estimate was considered. Potential publication biases were assessed with the funnel plot, as well as the Egger and begg tests. Sensitivity analyses were conducted to estimate the influence of individual studies from the meta-analysis. All statistical tests were conducted using R-based open-source meta-analysis software (version 2.14.2).

\section{Results}

\section{Description of the studies}

After searching the databases, 1,376 records were fully reviewed (Figure 1). However, 1,165 were excluded after screening of titles and abstracts. Another 184 studies were excluded for the following reasons: they were laboratory studies or irrelevant studies, study sample sizes were too small, and they were duplicate articles or provided no LRR or survival outcome data. Another 26 articles were further excluded because essential results could not be extracted from the data. Finally, ten studies met the criteria for evaluation, comprising 29,860 cases $[9,10,12-20]$. Cohorts ranged from $88-15,315$ patients, and studies were published between 2004 and 2019. The main features of the eligible studies included are summarized in Table 1.

\section{Impact of PMRT on LRR in patients with ypNO breast cancer}

Data for the effect of PMRT on LRR were available from ten studies, accounting for 2,861 patients. We evaluated the association between PMRT and LRR in the entire group and in subgroups to determine their contribution. Among those patients with ypNO breast cancer, the estimated pooled RR for all studies showed that PMRT significantly reduced LRR in patients compared with those in the non-PMRT group (RR, $0.38 ; 95 \% \mathrm{Cl}, 0.19-0.77, P=0.007$; Figure $2 \mathrm{~A}$ ). As the heterogeneity among studies was significant $\left(\mathrm{I}^{2}\right.$ $=83.5 \%, P<0.001)$, the random-effects model was applied. The funnel plot and Egger's test indicated that slight asymmetry in the presence of publication bias of the included literature (Supplementary Figure S1 and Supplementary Table S1). One-way sensitivity analysis confirmed the stability across the included studies.

Subgroup analyses were performed for LRR on the effect of PMRT in various tumor stages. Since heterogeneity across studies was not significant $\left(I^{2}=0.0 \%, P=0.48\right)$, the fixed effects model was applied. We noted that PMRT was associated with a lower LRR rate (RR, $0.21 ; 95 \% \mathrm{Cl}, 0.12-0.40, P<0.001)$ in patients with less than stage III disease (Figure 2B). Among those with stage III-IV breast cancer, the LRR rate was also significantly reduced for breast cancer patients in the PMRT group compared with those in the non-PMRT group (RR, $0.16 ; 95 \% \mathrm{Cl}, 0.07-0.37, P<0.001$; Figure $2 \mathrm{C}$ ), which the heterogeneity among studies was not significant $\left(I^{2}=0.0 \%, P=0.61\right)$.

\section{Effects of PMRT on disease free survival (DFS) in patients with ypNO breast cancer}


The pooled RR for DFS was available in five breast cancer studies. Since the heterogeneity among studies was significant $\left(I^{2}=79.0 \%, P<0.001\right)$, the relationship between PMRT and DFS was evaluated using the random effects model. The estimated pooled RR in the PMRT group was not associated with a high DFS rate compared with patients in the non-PMRT group (RR, 0.70; 95\% $\mathrm{Cl}, 0.21-2.27, P=0.55$; Figure $3 \mathrm{~A}$ ). The results showed that no variable significantly influenced the RR estimate (Supplementary Figure S1 and Supplementary Table S1).

\section{Effects of PMRT on overall survival (OS) in patients with ypNO breast cancer}

PMRT impact on OS was available in nine ypNO breast cancer studies. The pooled RR was used to analyze survival outcomes in patients who received PMRT. The random model was applied, as heterogeneity across studies was significant $\left(I^{2}=79 \%, P<0.001\right)$. The results showed no significantly longer OS (RR, 0.81; 95\% Cl, 0.64-1.04, $P=0.10$, Figure 3B) in patients in the PMRT group compared with those in the non-PMRT group. No significant publication bias was detected by the funnel plot and Egger's test (Supplementary Figure S1 and Supplementary Table S1). In sensitive analysis, the results for OS showed the stability across the included studies.

\section{Discussion}

Currently, there are no published randomized trials to guide the impact of PMRT on breast cancer patients treated with NAC, particularly in patients who are ypNO and in whom the advantage of PMRT is not known. This meta-analysis is the first study to investigate the efficacy of PMRT in breast cancer patients who received NAC. We confirmed that radiation could reduce the LRR rate $(P=0.007) \unrhd$ particularly in patients with stage III-IV breast cancer (RR, 0.16; $P<0.001)$ after NAC and postmastectomy in ypN0 patients. In contrast, DFS (RR, 0.70; $P=0.55)$ and OS (RR, $0.81 ; P=0.10)$ wasn't significantly improved in the PMRT compared with the non-PMRT group. It was not surprising that the benefits of PMRT in the current study were similar to those reported after adjuvant chemotherapy $[8,21]$.

Multivariable analysis revealed that administration of PMRT to ypN2-3 women was associated with improved LRRQ DFS and OS [22, 23]. Since node-positive is an independent prognostic factor in breast cancer, we wondered what indications had the potential to result in a downstaging of the pathological extent of disease following NAC. A retrospective study revealed that in patients receiving primary systemic treatment and mastectomy, there was a significant reduction in the 5-year LRR rate in the PMRT group $(24 \%$ vs. $4 \%, P<0.001)$ after a median of 75 months of follow-up in 162 patients with ypN0 breast cancer [24]. In our analysis, the data evaluated the benefit derived from PMRT in patients receiving NAC and mastectomy for their locally advanced breast cancer. The results identified PMRT as a significant predictor of reduced LRR $(P=0.007)$. These results are consistent with previous reports, including the studies from the MD Anderson Cancer Center.

However, whether PMRT improves survival outcomes in patients with ypNO breast cancer after NAC is unclear. Recent retrospective data from Korea showed that PMRT was not associated with a difference in 
DFS or OS for patients with clinical stage II-III breast cancer who were ypNO [15]. The present study confirmed that PMRT did not improve DFS or OS in patients with ypNO breast cancer who received PMRT following primary systemic treatment. Therefore, the preliminary insights from this analysis suggest that PMRT did not provide any survival benefit in patients, similar to what has been reported previously, although additional data are needed to confirm these findings. A longer follow-up time may allow the significant benefit seen in LRR to translate to an increased benefit in OS. Additionally, a number of other risk factors, such as molecular typing of cancer and comorbidities, might also affect both DFS and OS.

This study had some limitations. First, despite knowing the clinical disease stage before NAC, there may be other factors such as ER/PR status or pathologic stage after NAC that could influence patient selection for PMRT among those with ypNO breast cancer. Second, this was a retrospective analysis where radiation was not a randomized variable. In an effort to reduce the potential for selection biases, this may have affected whether patients did or did not receive radiation. In addition, in subgroup analyses, for some of the subgroups, the sample size was limited, so we could not obtain conclusive results from patients with earlier stage disease.

\section{Conclusions}

In summary, our results strongly suggest that PMRT is associated with reduced LRR, particularly in stage III-IV breast cancer patients. However, PMRT was not associated with improved survival benefit among those with ypNO breast cancer after NAC. A prospective randomized study, such as the ongoing NSABP B51/RTOG 1304 trial (ClinicalTrials.gov, NCT01872975), will be needed to confirm our results and serve as guidance for selecting the optimal radiotherapy regimen for ypNO breast cancer patients.

\section{Declarations}

\section{Acknowledgements}

We thank Mark Abramovitz, PhD, from Liwen Bianji, Edanz Group China (www.liwenbianji.cn/ac), for editing the English text of a draft of this manuscript.

\section{Authors' contributions}

Conception/design: Ke Wang, Jian Huang

Provision of study material or patients: Ke Wang,Xiuyan Yu

Collection and/or assembly of data: Weilan Wang

Data analysis and interpretation: Ke Wang, Xiaoyan Jing,

Manuscript writing: Ke Wang, Xiaoyan Jing 


\section{Authors' information}

The authors are work in Second Affiliated Hospital of Zhejiang University School of Medicine

\section{Funding}

This work was supported by funds from Natural Science Foundation of Zhejiang Province (Grant No. LY18H160001).

\section{Availability of data and materials}

All data generated or analysed during this study are included in this published article\and referenced articles are listed in the References section.

\section{Ethics approval and consent to participate}

Not applicable.

\section{Consent for publication}

Not applicable.

\section{Competing interests}

The authors declare that they have no competing interests.

\section{References}

1. Fisher, A. Brown, E. Mamounas, S. Wieand, A. Robidoux, R.G. Margolese, A.B. Cruz, Jr., E.R. Fisher, D.L. Wickerham, N. Wolmark, A. DeCillis, J.L. Hoehn, A.W. Lees, N.V. Dimitrov, Effect of preoperative chemotherapy on local-regional disease in women with operable breast cancer: findings from National Surgical Adjuvant Breast and Bowel Project B-18, J Clin Oncol 15(7) (1997) 2483-93.

2. Kaufmann, G. von Minckwitz, E.P. Mamounas, D. Cameron, L.A. Carey, M. Cristofanilli, C. Denkert, W. Eiermann, M. Gnant, J.R. Harris, T. Karn, C. Liedtke, D. Mauri, R. Rouzier, E. Ruckhaeberle, V. Semiglazov, W.F. Symmans, A. Tutt, L. Pusztai, Recommendations from an international consensus conference on the current status and future of neoadjuvant systemic therapy in primary breast cancer, Ann Surg Oncol 19(5) (2012) 1508-16.

3. Ebctcg, P. McGale, C. Taylor, C. Correa, D. Cutter, F. Duane, M. Ewertz, R. Gray, G. Mannu, R. Peto, T. Whelan, Y. Wang, Z. Wang, S. Darby, Effect of radiotherapy after mastectomy and axillary surgery on 10year recurrence and 20-year breast cancer mortality: meta-analysis of individual patient data for 8135 women in 22 randomised trials, Lancet 383(9935) (2014) 2127-35. 
4. Ohri, E. Moshier, A. Ho, S. Green, R. Rhome, M. Mazumdar, S. Powell, C.J. Tsai, Postmastectomy Radiation in Breast Cancer Patients With Pathologically Positive Lymph Nodes After Neoadjuvant Chemotherapy: Usage Rates and Survival Trends, Int J Radiat Oncol Biol Phys 99(3) (2017) 549-559.

5.E. Harris, J. Freilich, H.Y. Lin, M. Chuong, G. Acs, The impact of the size of nodal metastases on recurrence risk in breast cancer patients with 1-3 positive axillary nodes after mastectomy, Int J Radiat Oncol Biol Phys 85(3) (2013) 609-14.

6.G. Bazan, J.R. White, The Role of Postmastectomy Radiation Therapy in Patients With Breast Cancer Responding to Neoadjuvant Chemotherapy, Semin Radiat Oncol 26(1) (2016) 51-8.

7. Akyurek, G. Yavas, Role of postmastectomy radiation therapy after neoadjuvant chemotherapy in locally advanced breast cancer, Exp Oncol 35(4) (2013) 267-71.

8.L. Fowble, J.P. Einck, D.N. Kim, S. McCloskey, J. Mayadev, C. Yashar, S.L. Chen, E.S. Hwang, N. Athena Breast Health, Role of postmastectomy radiation after neoadjuvant chemotherapy in stage II-III breast cancer, Int J Radiat Oncol Biol Phys 83(2) (2012) 494-503.

9.G. Rusthoven, R.A. Rabinovitch, B.L. Jones, M. Koshy, A. Amini, N. Yeh, M.W. Jackson, C.M. Fisher, The impact of postmastectomy and regional nodal radiation after neoadjuvant chemotherapy for clinically lymph node-positive breast cancer: a National Cancer Database (NCDB) analysis, Ann Oncol 27(5) (2016) 818-27.

10. Le Scodan, J. Selz, D. Stevens, M.A. Bollet, B. de la Lande, C. Daveau, F. Lerebours, A. Labib, S. Bruant, Radiotherapy for stage II and stage III breast cancer patients with negative lymph nodes after preoperative chemotherapy and mastectomy, Int J Radiat Oncol Biol Phys 82(1) (2012) e1-7.

11.K. Parmar, V. Torri, L. Stewart, Extracting summary statistics to perform meta-analyses of the published literature for survival endpoints, Stat Med 17(24) (1998) 2815-34.

12.H. Huang, S.L. Tucker, E.A. Strom, M.D. McNeese, H.M. Kuerer, A.U. Buzdar, V. Valero, G.H. Perkins, N.R. Schechter, K.K. Hunt, A.A. Sahin, G.N. Hortobagyi, T.A. Buchholz, Postmastectomy radiation improves local-regional control and survival for selected patients with locally advanced breast cancer treated with neoadjuvant chemotherapy and mastectomy, J Clin Oncol 22(23) (2004) 4691-9.

13.E. McGuire, A.M. Gonzalez-Angulo, E.H. Huang, S.L. Tucker, S.W. Kau, T.K. Yu, E.A. Strom, J.L. Oh, W.A. Woodward, W. Tereffe, K.K. Hunt, H.M. Kuerer, A.A. Sahin, G.N. Hortobagyi, T.A. Buchholz, Postmastectomy radiation improves the outcome of patients with locally advanced breast cancer who achieve a pathologic complete response to neoadjuvant chemotherapy, Int J Radiat Oncol Biol Phys 68(4) (2007) 1004-9.

14.H. Bae, W. Park, S.J. Huh, D.H. Choi, S.J. Nam, Y.H. Im, J.S. Ahn, Radiation treatment in pathologic n0$\mathrm{n} 1$ patients treated with neoadjuvant chemotherapy followed by surgery for locally advanced breast 
cancer, J Breast Cancer 15(3) (2012) 329-36.

15.J. Shim, W. Park, S.J. Huh, D.H. Choi, K.H. Shin, N.K. Lee, C.O. Suh, K.C. Keum, Y.B. Kim, S.D. Ahn, S.S. Kim, S.W. Ha, E.K. Chie, K. Kim, H.S. Shin, J.H. Kim, H.S. Lee, The role of postmastectomy radiation therapy after neoadjuvant chemotherapy in clinical stage II-III breast cancer patients with pNO: a multicenter, retrospective study (KROG 12-05), Int J Radiat Oncol Biol Phys 88(1) (2014) 65-72.

16. Liu, K. Mao, S. Jiang, W. Jiang, K. Chen, B.Y. Kim, Q. Liu, L.K. Jacobs, The role of postmastectomy radiotherapy in clinically node-positive, stage II-III breast cancer patients with pathological negative nodes after neoadjuvant chemotherapy: an analysis from the NCDB, Oncotarget 7(17) (2016) 24848-59.

17.L. Rong, S.L. Wang, Y. Tang, J. Jin, Y.W. Song, W.H. Wang, Y.P. Liu, H. Fang, H. Ren, X.F. Liu, Z.H. Yu, Y.X. $\mathrm{Li}$, [The role of postmastectomy radiotherapy in clinical T1-3N1M0 breast cancer patients with pathological negative lymph nodes after neoadjuvant chemotherapy and mastectomy], Zhonghua Zhong Liu Za Zhi 39(6) (2017) 445-452.

18. Kantor, C. Pesce, P. Singh, M. Miller, J. Tseng, C.H. Wang, D.J. Winchester, K. Yao, Post-mastectomy radiation therapy and overall survival after neoadjuvant chemotherapy, J Surg Oncol 115(6) (2017) 668676.

19. Cao, D. Ou, K.W. Shen, G. Cai, R. Cai, F. Xu, S.G. Zhao, C. Xu, N. Grellier Adedjouma, Y.M. Kirova, J.Y. Chen, Outcome of postmastectomy radiotherapy after primary systemic treatment in patients with clinical T1-2N1 breast cancer, Cancer Radiother 22(1) (2018) 38-44.

20. Miyashita, N. Niikura, H. Kumamaru, H. Miyata, T. Iwamoto, M. Kawai, K. Anan, N. Hayashi, K. Aogi, T. Ishida, H. Masuoka, K. lijima, S. Masuda, K. Tsugawa, T. Kinoshita, H. Tsuda, S. Nakamura, Y. Tokuda, Role of Postmastectomy Radiotherapy After Neoadjuvant Chemotherapy in Breast Cancer Patients: A Study from the Japanese Breast Cancer Registry, Ann Surg Oncol (2019).

21. Ragaz, S.M. Jackson, N. Le, I.H. Plenderleith, J.J. Spinelli, V.E. Basco, K.S. Wilson, M.A. Knowling, C.M. Coppin, M. Paradis, A.J. Coldman, I.A. Olivotto, Adjuvant radiotherapy and chemotherapy in node-positive premenopausal women with breast cancer, N Engl J Med 337(14) (1997) 956-62.

22. Overgaard, P.S. Hansen, J. Overgaard, C. Rose, M. Andersson, F. Bach, M. Kjaer, C.C. Gadeberg, H.T. Mouridsen, M.B. Jensen, K. Zedeler, Postoperative radiotherapy in high-risk premenopausal women with breast cancer who receive adjuvant chemotherapy. Danish Breast Cancer Cooperative Group 82b Trial, N Engl J Med 337(14) (1997) 949-55.

23. Overgaard, M.B. Jensen, J. Overgaard, P.S. Hansen, C. Rose, M. Andersson, C. Kamby, M. Kjaer, C.C. Gadeberg, B.B. Rasmussen, M. Blichert-Toft, H.T. Mouridsen, Postoperative radiotherapy in high-risk postmenopausal breast-cancer patients given adjuvant tamoxifen: Danish Breast Cancer Cooperative Group DBCG 82c randomised trial, Lancet 353(9165) (1999) 1641-8. 
24. Nagar, E.A. Mittendorf, E.A. Strom, G.H. Perkins, J.L. Oh, W. Tereffe, W.A. Woodward, A.M. GonzalezAngulo, K.K. Hunt, T.A. Buchholz, T.K. Yu, Local-regional recurrence with and without radiation therapy after neoadjuvant chemotherapy and mastectomy for clinically staged T3NO breast cancer, Int J Radiat Oncol Biol Phys 81(3) (2011) 782-7.

\section{Table}

Table 1. Selected characteristics of studies in the meta-analysis.

\begin{tabular}{|c|c|c|c|c|c|c|c|c|}
\hline Study & Country & Year & $\begin{array}{l}\text { No. of } \\
\text { patients }\end{array}$ & $\begin{array}{l}\text { Patholo- } \\
\text { gical } \\
\text { stage }\end{array}$ & $\begin{array}{l}\text { Type of } \\
\text { surgery }\end{array}$ & $\mathrm{NAC}$ & Outcome & $\begin{array}{l}\text { Median } \\
\text { follow up } \\
\text { (Months) }\end{array}$ \\
\hline Huang & American & 2004 & 676 & II -IV & Mastectomy & $\mathrm{A} / \mathrm{T}, \mathrm{VACP}$ & LRR, & 69 \\
\hline McGuire & American & 2007 & 106 & I-III & Mastectomy & $\mathrm{A} / \mathrm{T}$ & LRR, OS & 62 \\
\hline Scodan & France & 2010 & 134 & II-III & Mastectomy & $\mathrm{A} / \mathrm{T}$ & $\begin{array}{l}\text { LRR,DFS, } \\
\text { OS }\end{array}$ & 91 \\
\hline Nagar & American & 2011 & 162 & II & Mastectomy & $\mathrm{A} / \mathrm{T}$ & LRR & 75 \\
\hline $\mathrm{Bae}$ & Korean & 2012 & 98 & 0 - III & Mastectomy & $\mathrm{NR}$ & $\begin{array}{l}\text { LRR,DFS, } \\
\text { OS }\end{array}$ & 42 \\
\hline Shim & Korea & 2013 & 151 & II-III & Mastectomy & $\mathrm{A} / \mathrm{T}$ & $\begin{array}{l}\text { LRR, } \\
\text { OS,DFS }\end{array}$ & 59 \\
\hline Liv & American & 2015 & 1560 & II -III & Mastectomy & $\mathrm{NR}$ & OS & 56 \\
\hline $\begin{array}{l}\text { Rusthove- } \\
\text { n }\end{array}$ & American & 2016 & 3040 & II -III & Mastectomy & $\mathrm{NR}$ & OS & 41 \\
\hline Kantor & American & 2016 & 8321 & I-III & Mastectomy & $\mathrm{NR}$ & OS & 69 \\
\hline Qinlin & China & 2017 & 185 & II - III & Mastectomy & $\mathrm{A} / \mathrm{T}$ & $\begin{array}{l}\text { LRR, DFS } \\
\text { OS }\end{array}$ & 70 \\
\hline $\mathrm{CaO}$ & China & 2017 & 88 & I-III & Mastectomy & $\mathrm{A} / \mathrm{T}$ & $\begin{array}{l}\text { LRR,DFS, } \\
\text { OS }\end{array}$ & 67 \\
\hline Miyashita & Japan & 2019 & 3226 & I-III & Mastectomy & $\mathrm{NR}$ & $\begin{array}{l}\text { LRR,DDFS, } \\
\text { OS }\end{array}$ & $>60$ \\
\hline
\end{tabular}

Abbreviations: NAC neoadjuvant chemotherapy; A anthracycline-based

chemotherapy; $\mathrm{A} / \mathrm{T}$ anthracycline- or taxane- based chemotherapy; $\mathrm{NR}$, no report;

LRR, local-regional recurrence; DFS, disease-free survival; OS overall survival. 
Figures

Records identified through database searching $(n=1363)$
Additional records identified

through other sources $(n=13)$

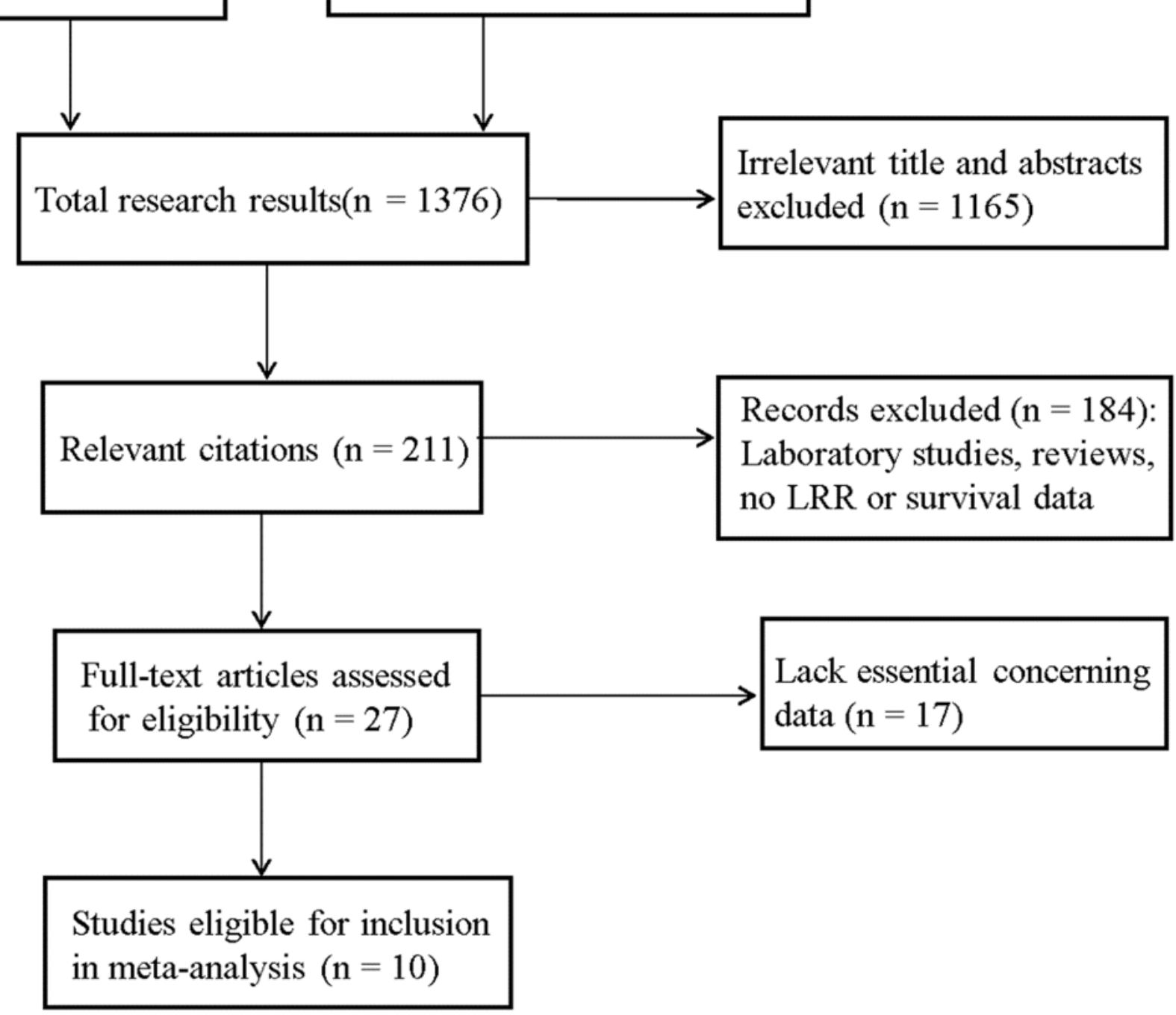

Figure 1

Study flow chart. 
Records identified through database searching $(n=1363)$
Additional records identified

through other sources $(n=13)$

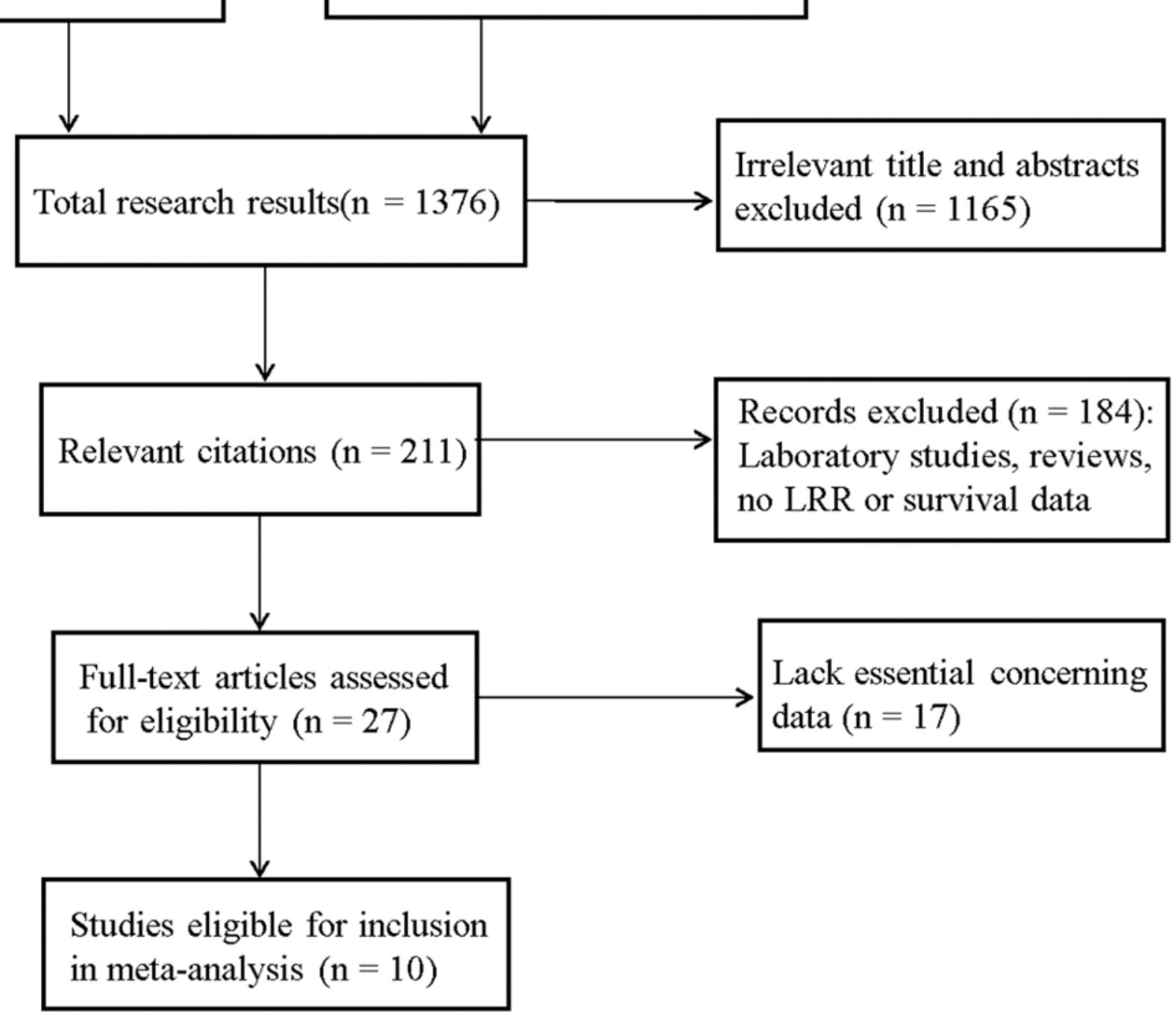

Figure 1

Study flow chart. 
A Impact of PMRT on LRR (Overall population)

Stuchy

Risk Ratio

Huang 542/134

Nagar $119 / 43$

McGuire 72/34

Bae 56/42

Shim $105 / 46$

Qinlin $89 / 96$

Cao $44 / 9$

Scodan $77 / 56$

Miyashita 183/1114

Random effects model

Heterogeneity: $f^{2}=83 \%, \tau^{2}=0.7409, \gamma_{0}^{k}=48.42(0<0.01)$

$\begin{array}{llll}0.1 & 0.51 & 2 & 10\end{array}$

Lower LRR Higher LRR
B Impact of PMRT on LRR (Stage < III)
95\%-CIWeight

$0.38[0.25 ; 0.58] 16.3 \%$

$0.14[0.05 ; 0.39] 12.8 \%$

$0.44[0.12 ; 1.65] 10.8 \%$

$0.74[0.16 ; 3.45] \quad 9.4 \%$

$0.28[0.05 ; 1.61] \quad 8.3 \%$

$0.14[0.02 ; 1.15] \quad 6.9 \%$

$0.17[0.03 ; 1.00] \quad 8.1 \%$

$0.41[0.10 ; 1.65] 10.3 \%$

$1.27[1.01 ; 1.59] 17.0 \%$

$0.38[0.19 ; 0.77] 100.0 \%$
Stuchy

Huang $91 / 66$

McGuire 10/20

Nagar $119 / 43$

Qinlin 35/66

Cao $75 / 13$

Scodan $39 / 44$

Heterogeneity: $\gamma^{2}=0 \%, \tau^{2}=0, \gamma_{5}^{2}=4.52(p=0.48)$

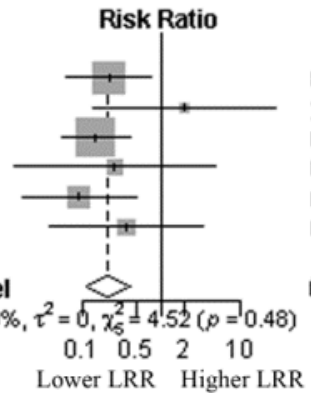

Fixed effect model
RR 95\%-CIWeight

$0.22[0.06 ; 0.76] 28.9 \%$ $2.00[0.14 ; 28.76] \quad 1.8 \%$ $0.14[0.05 ; 0.39] 41.0 \%$ $0.26[0.01 ; 4.81] \quad 6.7 \%$ $0.09[0.02 ; 0.48] 14.0 \%$ $0.36[0.04 ; 3.31] \quad 7.6 \%$

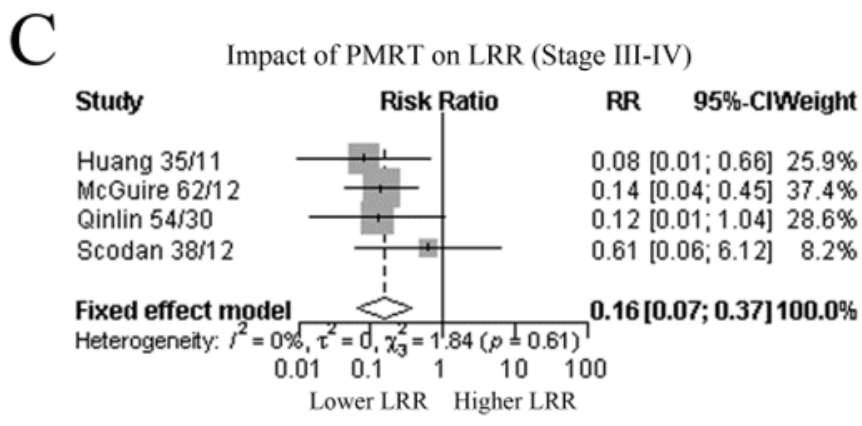

Figure 2

Forrest plot of RR used to evaluate the association between PMRT and LRR. (A) Overall population; (B) Stage less than III breast cancer; (C) Stage III-IV breast cancer. RR values with $95 \%$ confidence intervals for survival are associated with PMRT group versus no PMRT group; RR less than 1 represents a lower risk of recurrence. The pooled results that patients with PMRT had significantly reduced LRR. Abbreviations: PMRT, Postmastectomy radiation therapy; LRR, local-regional recurrence. 
A Impact of PMRT on LRR (Overall population)

Stuchy

Risk Ratio

Huang 542/134

Nagar $119 / 43$

McGuire 72/34

Bae 56/42

Shim $105 / 46$

Qinlin $89 / 96$

Cao 44/9

Scodan $77 / 56$

Miyashita 183/1114

Random effects model

Heterogeneity: $i^{2}=83 \%, \tau^{2}=0.7409, \gamma_{0}^{k}=48.42(\beta<0.01)$

$\begin{array}{llll}0.1 & 0.51 & 2 & 10\end{array}$

Lower LRR Higher LRR
B Impact of PMRT on LRR (Stage < III)
95\%-CIWeight

Stucty

$0.38[0.25 ; 0.58] 16.3 \%$

$0.14[0.05 ; 0.39] 12.8 \%$

$0.44[0.12 ; 1.65] 10.8 \%$

$0.74[0.16 ; 3.45] \quad 9.4 \%$

$0.28[0.05 ; 1.61] \quad 8.3 \%$

$0.14[0.02 ; 1.15] \quad 6.9 \%$

$0.17[0.03 ; 1.00] \quad 8.1 \%$

$0.41[0.10 ; 1.65] 10.3 \%$

$1.27[1.01 ; 1.59] 17.0 \%$

$0.38[0.19 ; 0.77] 100.0 \%$
Huang $91 / 66$

McGuire 10/20

Nagar $119 / 43$

Qinlin 35/66

Cao 75/13

Scodan 39/44

Fixed effect model

Heterogeneity: $\gamma^{2}=0 \%, \tau^{2}=0, x_{5}^{2}=4.52(p=0.48)$

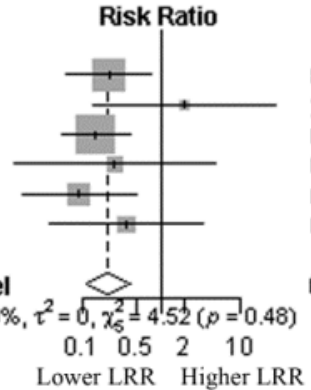

RR 95\%-CIWeight

$0.22[0.06 ; 0.76] 28.9 \%$ $2.00[0.14 ; 28.76] \quad 1.8 \%$ $0.14[0.05 ; 0.39] 41.0 \%$ $0.26[0.01 ; 4.81] \quad 6.7 \%$ $0.09[0.02 ; 0.48] 14.0 \%$ $0.36[0.04 ; 3.31] \quad 7.6 \%$

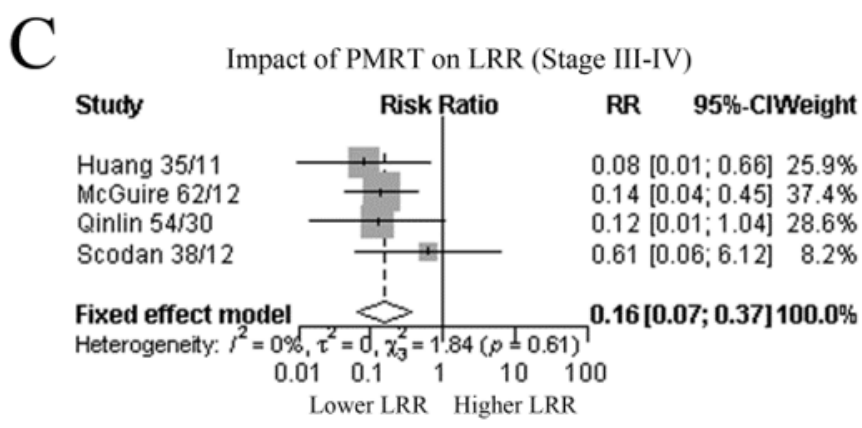

Figure 2

Forrest plot of RR used to evaluate the association between PMRT and LRR. (A) Overall population; (B) Stage less than III breast cancer; (C) Stage III-IV breast cancer. RR values with $95 \%$ confidence intervals for survival are associated with PMRT group versus no PMRT group; RR less than 1 represents a lower risk of recurrence. The pooled results that patients with PMRT had significantly reduced LRR. Abbreviations: PMRT, Postmastectomy radiation therapy; LRR, local-regional recurrence. 


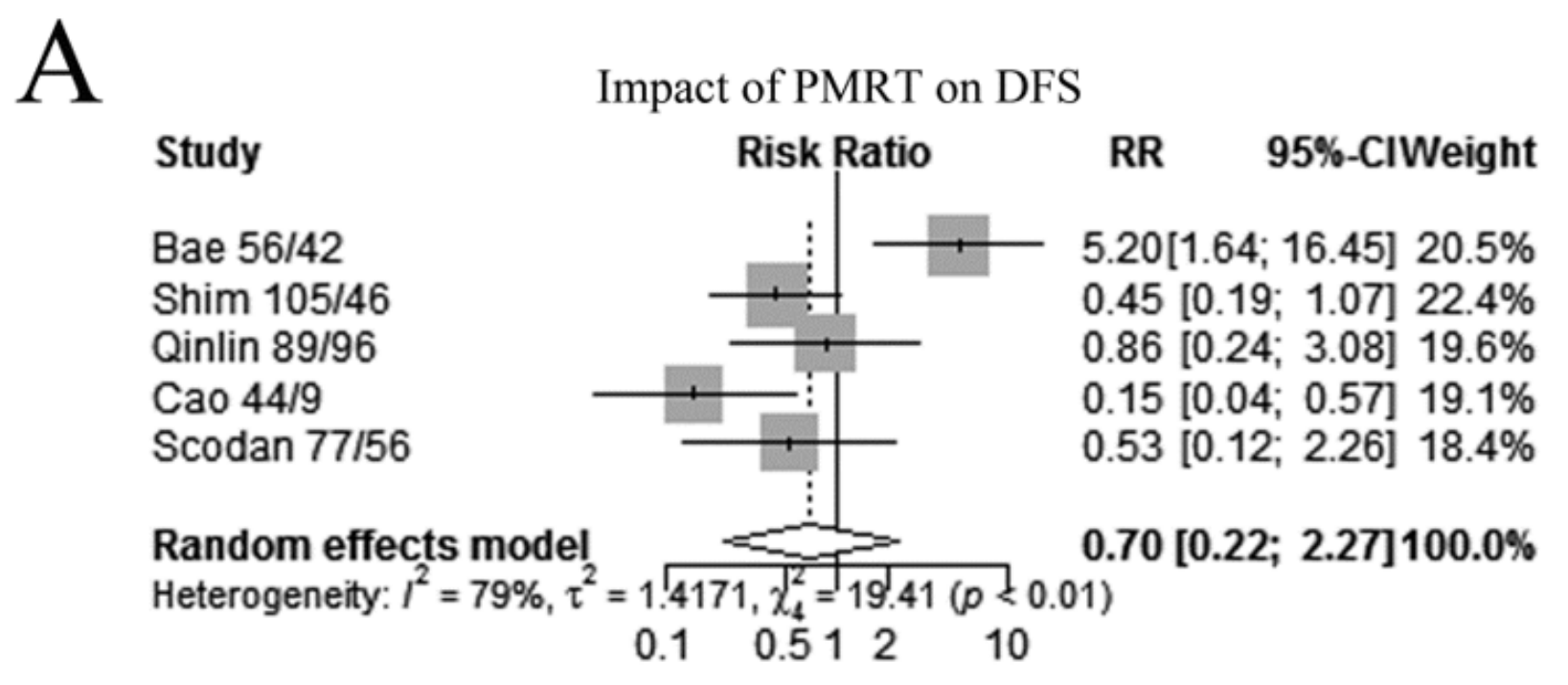

\section{Impact of PMRT on OS}

\begin{tabular}{|c|c|c|}
\hline Study & Risk Ratio & 95\%-ClWeight \\
\hline McGuire 72/34 & + & $0.33[0.20 ; 0.54] 11.8 \%$ \\
\hline Bae $56 / 42$ & & $1.50[0.40 ; 5.65] \quad 3.0 \%$ \\
\hline Kantor $6081 / 2303$ & & $0.79[0.73 ; 0.84] 21.8 \%$ \\
\hline Shim $105 / 46$ & & $0.61[0.21 ; 1.83] \quad 4.1 \%$ \\
\hline Liu 904i657 & & $0.84[0.67 ; 1.05] 18.8 \%$ \\
\hline Rusthoven $1962 / 1078$ & & $0.77[0.64 ; 0.93] 19.7 \%$ \\
\hline Qinlin 89/96 & & $0.08[0.00 ; 1.45] \quad 0.7 \%$ \\
\hline Scodan $122 / 56$ & & $1.38[0.39 ; 4.89] \quad 3.2 \%$ \\
\hline Miyashita $144 / 1114$ & + & $1.56[1.17 ; 2.08] 17.0 \%$ \\
\hline
\end{tabular}

Figure 3

Meta-analysis of relative risk (RR) for the correlation between PMRT and survival outcomes. (A) DFS in PMRT and no-PMRT group; (B) OS in PMRT and no-PMRT group. RR less than 1 represents a lower risk of progression or death. The analysis showed that patients with PMRT was no correlation with a difference in DFS and OS. 


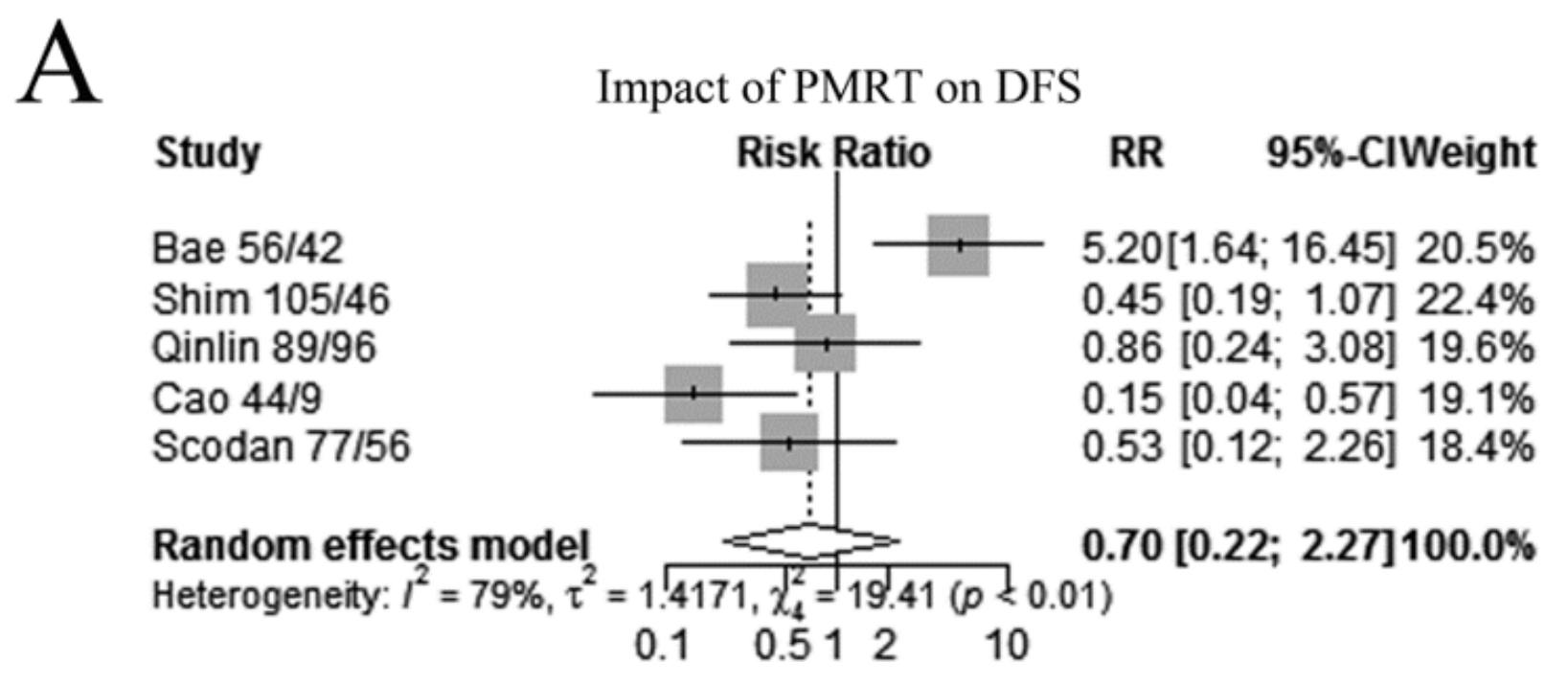

\section{Impact of PMRT on OS}

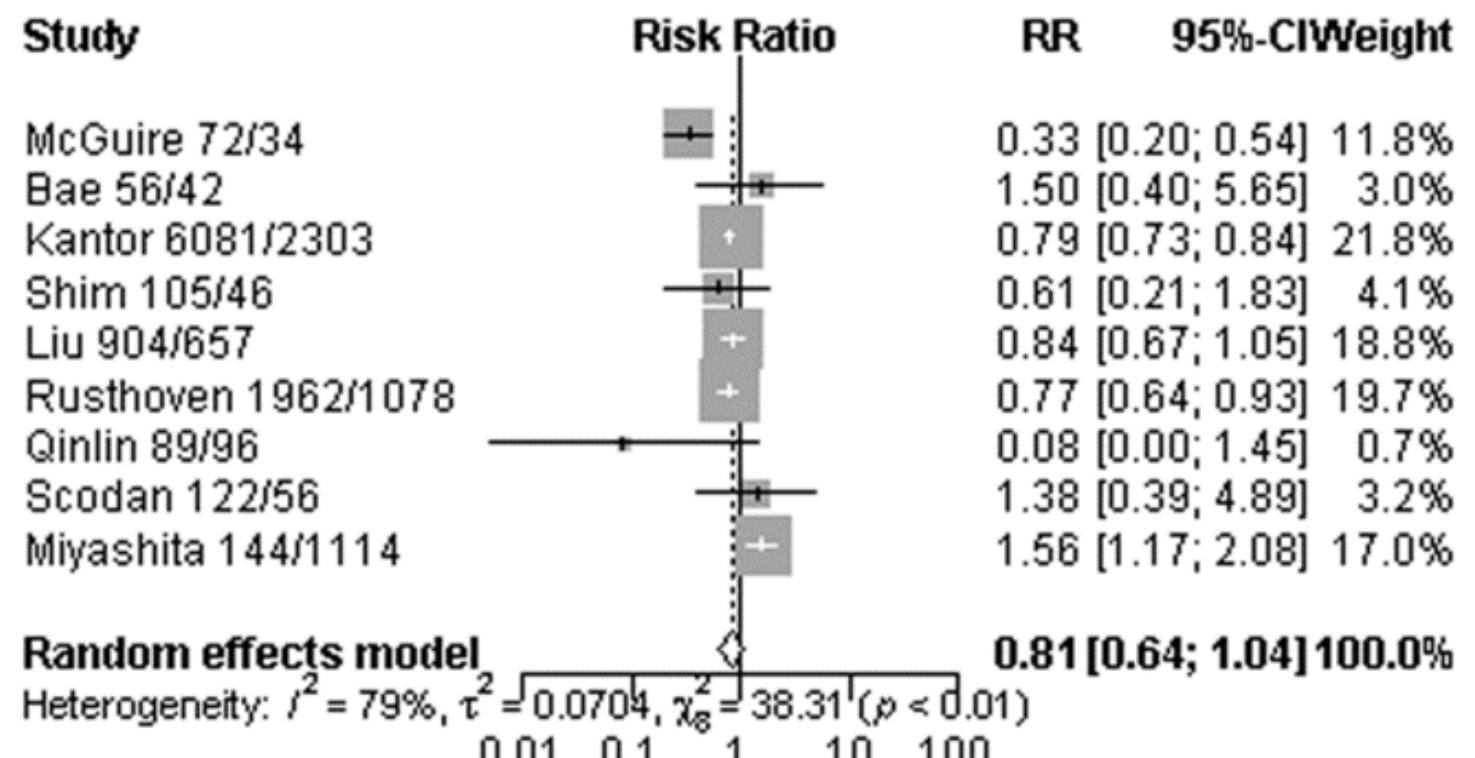

Figure 3

Meta-analysis of relative risk (RR) for the correlation between PMRT and survival outcomes. (A) DFS in PMRT and no-PMRT group; (B) OS in PMRT and no-PMRT group. RR less than 1 represents a lower risk of progression or death. The analysis showed that patients with PMRT was no correlation with a difference in DFS and OS. 


\section{Supplementary Files}

This is a list of supplementary files associated with this preprint. Click to download.

- SupplementarytableS1.docx

- Figures1.tif

- Figures1.tif 